\title{
Willian Hazlitt: Um crítico de arte sob o signo da revolução
}

\author{
Pedro Paulo Pimenta ${ }^{1}$ \\ pedronamba@gmail.com \\ Universidade de São Paulo (USP), São Paulo, Brasil
}

resumo 0 artigo propõe-se a reconstruir a trajetória de William Hazlitt, procurando mostrar que sua formação como crítico de arte esteve estreitamente ligada a certos eventos decorrentes da Revolução Francesa. Um elemento nesta direção é representado pela sua visitação, a partir da virada para o século XIX, ao Louvre. Refletindo sobre sua experiência parisiense, o crítico formula a ideia de que a linguagem da pintura almeja uma universalidade inimaginável no âmbito da política. Com isso, busca-se sugerir a existência de alguma espécie de nexo entre esses dois fenômenos aparentemente desconectados.

palavras-chave Revolução Francesa; crítica; pintura; plástica; universalidade; política

Uma vida entre os quadros, dedicada ao estudo e ao amor pela arte, é um sonho feliz e tranquilo; ou melhor, é sonhar e estar acordado ao mesmo tempo... ${ }^{2}$

Às vezes sonho que estou no Louvre, que pergunto pelas obras dos grandes mestres, que não as encontro ou que foram adulteradas ou destruídas - e então acordo, aos gritos! $!^{3}$

Em 1802, o jovem inglês William Hazlitt (1778 - 1832), ainda indeciso entre as carreiras de pintor e de escritor, está entre os muitos que afluem a Paris para conhecer a "galeria" (como então era chamada) do Louvre, uma das instituições inaugurada pela Revolução. O palácio real do Louvre, que reunia a maior parte da coleção da coroa, torna-se museu em 1797, com 
direção própria e aberto gratuitamente ao público (ou aos “cidadãos”). À coleção real são anexadas obras de coleções particulares e, posteriormente, de espólio de guerra. A par da coleção permanente, mantêm-se os salões anuais do antigo regime e organizam-se exposições periódicas. Em meio a hostilidades entre França e Inglaterra, vive-se em 1802 um período de paz, graças ao Tratado de Amiens (promulgado em março desse ano), e a ida de ingleses ao continente é livre ${ }^{4}$ É como copista que Hazlitt chega ao museu, tendo aceitado uma comissão para reproduzir telas famosas.

Anos depois, em 1821, num ensaio sobre "Os prazeres da pintura”, ele relembra essa experiência marcante:

Quando fui ao Louvre estudar, eu já havia realizado algum progresso na arte da pintura; depois disso, abadonei-a. Como poderia esquecer a sensação que experimentei, ao folhear o catálogo que um amigo me emprestara por ocasião de minha partida? Os quadros, os nomes dos pintores, pareciam estalar na boca... Pensei que a maior honra que eu poderia oferecer aos transcendentes méritos dessas produções seria não me sentir desapontado ao vê-las diante de mim. A verdade é que a contemplação de outras obras desses mesmos mestres me permitira formar uma ideia vaga, mas não distorcida, do que estava prestes a encontrar. - Em meu primeiro dia no Louvre, só recebi permissão para visitar a galeria dos pintores franceses, e cheguei a pensar que não veria os Mestres Antigos. Pude entrevê-los pela fresta de uma porta (vil obstáculo!), como quem do purgatório vê o paraíso... Por fim, graças a minha impertinência, fui admitido nessa outra galeria, e não perdi um instante no usufruto do privilégio. Posso dizer que tive un beau jour. Caminhei encantado por um quarto de milha contendo os mais esplêndidos esforços da mente humana, um mundo inteiro de gênio, um universo de arte! Prescrutei cada uma das escolas, de cima a baixo; e no fim fui admitido na galeria interna, em que estavam sendo restauradas algumas das mais importantes peças do acervo.Vi a Transfiguração, o Martírio de são Pedro, o São Jerônimo de Domenichino, apoiados no chão, como camelos em repouso, com as pernas dobradas, exibindo suas riquezas ao espectador... Ao longo de quatro meses, vivi e estudei nessas galerias, ouvi todos os dias o aviso, Quatre heures pasés, il faut fermer, citoyens!, pronunciado com ríspido sotaque da província, e trouxe comigo desenhos e fragmentos, dos quais tive que abrir mão, como gotas de 
sangue, em troca de dinheiro. Quantas vezes, oh quantas vezes, magnífico e divino palácio, não retornou a vós o meu coração peregrino! $!^{5}$

As galerias percorridas por Hazlitt haviam sido abertas recentemente, em 1800. Para que se tenha uma ideia da profusão que ali havia de tesouros dos mestres "modernos" (que a essa altura já haviam se tornado “antigos”), o Louvre contava, na época, entre outras preciosidades, com mais de vinte telas atribuídas a Rafael, outras tantas a Ticiano, mais de trinta a Carracci. Como um dentre os muitos estudiosos ou copistas que afluem ao museu nessa época e imprimem a ele a vocação de uma instituição formadora, Hazlitt confirma no Louvre sua predileção pelos Old Masters. Sua epifania não se confunde com a reação atônita do mero turista que se vê diante de quadros famosos. Para os "infinitamente numerosos cavalheiros e amantes da arte em visita a Paris", observa Hazlitt, "a ida ao Louvre é apenas mais um dos eventos de sua viagem, não um evento decisivo em suas vidas, depois lembrado com gratidão e saudade (regret)". ${ }^{6}$ Hazlitt, por sua vez, sabe bem onde está e tira proveito da oportunidade: escolhe seus quadros prediletos; desenha-os; observa o processo de restauração das obras; compara as imagens que tem diante de si com a ideia que formara dos quadros a partir de reproduções em catálogos.

Sobretudo, Hazlitt descobre que algo separa a arte da pintura da arte de escrever. Diferentemente da escrita, que "traduz sensações (feelings) em palavras, a pintura traduz nomes de coisa em coisas, e nunca se torna cansativa", renova o atrativo do que é da natureza e mostra "não o que já conhecemos", mas algo cuja existência “acabamos de descobrir". 7 O prazer da pintura é tanto intelectual quanto físico, a pintura "é uma arte mecânica, bem como liberal", em que o corpo do artista experimenta a sensação de "poder" decorrente da produção de efeitos a partir de concepções de sua mente. $\mathrm{O}$ tato e a visão, as mãos e os olhos se combinam para realizar, ao longo de "semanas e meses", um objeto de acordo com uma ideia". A pintura, diferentemente da escritura, "não é uma ocupação sedentária, requer não tanto a explosão quanto o exercício contínuo e constante de força muscular. A precisão e a delicadeza da operação manual compensam a falta de veemência" dessa arte que, se não tem à disposição o uso das palavras para expressar sentimentos, exibe "o poder ou a paixão" enquanto "definem um objeto", pela forma ou pela cor; "coisas sem expressão" 
aparecem nessa imitação de objetos naturais por signos naturais dotadas de um "caráter cuja verdade é dada pela verdade da sensação". ${ }^{9}$ A constatação dessas diferenças obriga Hazlitt a decidir entre pintar e escrever. Sua escolha é por esta última arte: "desde então abdiquei de toda aspiração a exercer a pintura como profissão" ${ }^{10}$. Teria aberto mão de expressar a "verdade da sensação"?

\section{$* * *$}

Deparar com quadros de antigos mestres numa galeria ou museu não é como encontrá-los no estúdio ou no ambiente para o qual originalmente foram concebidos (uma igreja, um palácio, uma mansão etc.). Extraída de seu contexto original, a tela que agora temos diante de nós é um produto novo, necessariamente incompleto em relação ao original: tal como um organismo, extraída de seu entorno, ela perde algo de sua naturalidade e vitalidade. Como mostram as palavras de Hazlitt, a experiência do gosto se desloca dos espaços restritos e relativamente calmos em que antes se realizava para ocorrer em meio ao tumulto que, já em 1802, é indissociável da frequentação de galerias públicas que exibem objetos de arte. No testemunho de Hazlitt, o Louvre e suas salas mal se dissociam das "obras-primas" que ali se encontram.

O museu parece ter se tornado o lugar natural para a observação e o estudo da arte, como sugere o fato de que nesse mesmo ano de 1802, encontre-se no Louvre ninguém menos que o pintor inglês Joseph Turner, realizando estudos de cor a partir de Ticiano, Poussin eVeronese ${ }^{11}$. De sua pintura, Hazlitt depois dirá que ela "representa propriamente não tanto os objetos da natureza quanto o meio em que eles são vistos" ${ }^{12}$. Saturadas de "atmosfera", as paisagens de Turner trairiam seu aprendizado da cor junto aos mestres que encontrara no "ambiente" das salas do Louvre?

Seja como for, nem todos concordariam com as impressões positivas que Hazlitt tem do museu, nem tampouco o recomendariam como lugar adequado para o aprendizado da arte. O crítico alemão Friedrich Schlegel, que também em 1802 se encontra no Louvre e redige, para benefício de um amigo, uma Descrição de quadros do Louvre, percebe o museu como "um lugar triste e sem forma, desses que convêm mais aos déspotas 
sem educação que aos gênios de séculos passados. É assim que entrou para os anais da história, não como um templo concebido para abrigar os mais sublimes monumentos das belas-artes" "13. O interesse de Schlegel, como o de Hazlitt e o de Turner, é pelas "obras de arte" propriamente ditas, ou seja, pelos mestres d'outrora. Repugnam-lhe "as experimentações dos modernos franceses" cujas "exposições” ocupam as salas outrora habitadas pelos "mestres do passado" (lembrando que a Academia de Belas-Artes era então presidida por Jacques-Louis David). ${ }^{14}$ Para Schlegel, que as telas se encontrem no Louvre é quase um obstáculo à sua apreciação, e é com desgosto que ele descreve as longas galerias em que estão dispostas "contra a parede" muitas obras-primas da grande arte. Em vivo contraste com a percepção desse ambiente retrógrado estão suas preciosas descrições dos tableuax - tomados em si mesmos, isolados, eles aparecem, em suas palavras, cheios de luz e de rica textura ${ }^{15}$.

\section{$* * *$}

A experiência parisiense de Hazlitt é o termo de um processo que vinha acontecendo há algum tempo. No mesmo ensaio em que recorda sua visita ao Louvre, ele explica que sua "primeira iniciação aos mistérios da arte ocorreu na Galeria Orléans; foi ali que formei meu gosto, tal como ele é”.

Senti-me estupefato quando vi as obras ali reunidas, contemplei-as com olhos deslumbrados e ardentes. Uma névoa se dissipou diante de meus olhos: as barreiras haviam caído. Um novo sentido se apoderou de mim, um novo céu e uma nova terra surgiram à minha frente ... Ouvíramos falar de nomes como Ticiano, Rafael, Domenichino, Caracci - mas encará-los face a face, encontrar-se no mesmo recinto que suas imortais produções, era como quebrar um poderoso encanto - era quase um efeito de necromancia! A partir desse momento, vivi num mundo de quadros. Batalhas, cercos, discursos no parlamento, tudo isso parecia mero ruído e fúria, que não significava nada, comparado às poderosas obras e aos veneráveis nomes que se dirigiam a mim no eterno silêncio do pensamento. O mais notável é que até então eu não somente ignorara como fora indiferente às belezas da arte ${ }^{16}$. 
Essa é a cena da conversão de Hazlitt, da expansão de sua sensibilidade. Esse episódio, ocorrido em 1799, na Inglaterra, está diretamente ligado aos eventos de 1789 na França ${ }^{17}$. Em 1792, o duque de Orléans, receando, justificadamente, os desdobramentos da Revolução Francesa, sugeridos pela rapidez com que os eventos se sucedem, transfere para a Inglaterra sua valiosa coleção de arte com o intuito de vendê-las num leilão. Seis anos depois, entre dezembro de 1798 e julho de 1799, as obras são finalmente exibidas ao público na Galeria Orléans, em Londres (o preço da entrada é 1 shilling), antes de serem leiloadas. Com isso, um público diferente, que não o da aristocracia, tem oportunidade de apreciar objetos que até então dificilmente se encontravam a seu alcance (ainda mais num país protestante como a Inglaterra).

$* * *$

Em seus anos de maturidade, Hazlitt frequenta assiduamente as exibições públicas que se multiplicam na Inglaterra. Em 1805, é inaugurada em Londres, na British Institution, uma mostra dedicada à arte dos grandes mestres do passado. Encontram-se ali, diferentemente do que ocorre na Royal Academy of Arts, instituição mais "nacionalista", as produções de pintores holandeses, belgas, italianos ou espanhóis. Em visita à exposição, Hazlitt comenta os critérios de organização e o Catalogue raisonée, censurando o desdém com que são tratados os mestres estrangeiros e exaltados os ingleses, numa espécie de "xenofobia" pictórica. Observa ele que

Patriotismo e belas-artes não combinam, pois o patriotismo está relacionado com vantagens excludentes, e as vantagens das belas-artes não são excludentes, mas comunicáveis... As belas-artes dependem de gosto e conhecimento. Não consumimos obras de arte como se fossem artigos de alimentação, de vestimenta ou de combustível; alimentamonos de sua ideia, que é acessível a todos e pode ser multiplicada sem fim... O conhecimento ou perfeição da arte em uma época ou país é a causa de sua existência ou perfeição em outro. A arte é causa da arte em outros homens. Obras de gênio realizadas por um holandês são causa de gênio em um inglês, são causa de gosto em um inglês. Apadrinhar as 
artes estrangeiras, não é impedir mas promover as artes na Inglaterra. A arte subsiste por comunicação, não por exclusão. ${ }^{18}$

O patriotismo é edificado sobre palavras, sobre discursos inflamados regidos pela férrea lógica da guerra, onde a sobrevivência de uma nação depende, em grande medida, da destruição de outra; as belas-artes também comunicam, mas sem palavras, em linguagem muda e universal. Exposições públicas, uma inovação de seu tempo, são ou deveriam ser, na opinião de Hazlitt, ocasiões para celebrar esse traço de humanidade que transcende o caráter nacional.

Consoante a esse sentimento é o elogio que Hazlitt dedica a Poussin, pintor francês que viveu em Roma e cuja paisagem Orionte cego em busca do sol (hoje no Metropolitan Museum of Art, Nova York) é a epítome, na British Gallery, daquilo de que a pintura é capaz: transmutar "pensamentos em coisas", "pintar ideias", "dar-nos a natureza como nunca a vimos, mas tal como gostaríamos de vê-la"19. A pintura de paisagem se encontra devidamente elevada à condição de gênero histórico, em que a natureza não é pano de fundo da ação humana, mas dá, em sua grandeza, a medida e a dimensão exata desta. É na natureza como "totalidade" (wholeness) que mesmo os mais heróicos ou patéticos gestos humanos adquirem sentido. Relatando uma conversa que teve com o maior poeta de seu tempo, William Wordsworth, Hazlitt diz que um sinal da inteligência do poeta é o gosto pelas paisagens de Poussin, é ter percebido nelas "unidade de desenho" (unity of design). Restituiu-se à pintura o valor de referência para a escrita. É pelo crivo das virtudes de Poussin, inclusive, que Hazlitt julga a poesia de Wordsworth; e o veredicto, embora favorável para o poeta, coloca-o abaixo do pintor. É que as palavras, especialmente as singelas, não têm a mesma energia que imagens sublimes, na expressão do "princípio da imaginação que torna tudo conducente a um mesmo fim"20.

***

O conhecimento assíduo da pintura não esgota, porém, a experiência de Hazlitt no domínio das artes plásticas. É certo que a comunicação que ocorre na pintura é mais que fluxo indeterminado de sensação. Mas a 
razão disso Hazlitt só descobre integralmente quando adquire gosto pela escultura - também numa exposição pública. No ensaio "On the pleasure of painting", essa descoberta é mencionada num parêntese - "I never liked any [sculptures] till I saw the Elgin Marbles" $-{ }^{21}$, referência aos frisos trazidos à Inglaterra por Lorde Elgin em 1798, dilapidados do Parthenon, em Atenas. Essas peças são adquiridas pelo governo inglês, que as exibe ao público a partir de 1816, no British Museum. Hazlitt escreveu quatro textos sobre os frisos do Parthenon. Nesses textos, encontra-se o que pode ser considerada a versão definitiva de sua "crítica da arte" (que é, ao mesmo tempo, uma "teoria da sensibilidade"), com observações que consolidam uma investigação que vinha se desenrolando ao longo de diferentes ensaios e que culmina com o surgimento de The plain speaker, em 1826 (sua última coletânea de ensaios; depois disso, Hazlitt se dedica integralmente à monumental história de Napoleão e da Revolução Francesa). Mas o que torna os frisos do Parthenon diferentes de outras esculturas, que Hazlitt certamente viu no Louvre ou na Itália ou em suas turnês pelas coleções particulares da Inglaterra? É que neles se encontra uma verdadeira

Lógica da forma. Dada uma parte, outra não pode ser a não ser tal como é. Há mútua compreensão e reação por todo o molde. O Apolo e outras antiguidades gregas não são tão igualmente simples e severos. Os membros traem a aparência de serem esculpidos em mármore, de exibirem cada uma das belezas recônditas, e de contrabalançarem-se uns aos outros, como as rimas no verso. Os Elgin Marbles são como prosa, harmoniosa, fluida, variada. ${ }^{22}$

O autor considera nada menos que um "milagre" que uma obra da arte humana tenha se igualado, em sua singularidade irredutível, à "magistral excelência" da natureza mesma. As esculturas do Parthenon "não parecem ser a superfície externa de um bloco de mármore duro e imóvel, parecem, isto sim, atuados por um mecanismo interno e compostos dos mesmos materiais, maleáveis e flexíveis, que o corpo humano". Com essa imitação perfeita da regra da natureza, que é força de movimento, a escultura comunica à sensibilidade algo que o "entendimento humano" pode conceber, mas jamais poderia se figurar para si mesmo - a maneira de atuação das causas naturais. ${ }^{23}$ No British Museum, o resenhista encontra exposta uma verdade que a pintura também sugere, ainda que com menos força e 
vitalidade. Poderia o ensaísta produzir, com certo uso da linguagem, algo equivalente? Sim, desde que descubra em si mesmo a "força plástica" ou "reatividade" espontânea que permite moldar, com as "energias e recursos de sua própria mente", as "primeiras impressões" que recebe das coisas; torna-se assim o "criador" de uma natureza, de uma "esfera mais alta" cheia de tudo o que é "belo e sublime" 24 .

\section{$* * *$}

Revolução política e constituição republicana não chegaram à Inglaterra, para decepção de Hazlitt e de outros ingleses de sua geração. Mas também ali prospera uma nova instituição, de caráter republicano, o museu nacional, recorte do espaço público, da cidade, em que os cidadãos se aproximam e intensificam o recíproco contato por meio de um sentimento difuso que aspira à universalidade. O museu público, seja na Paris da revolução, seja na Londres da reação, faz as vezes de um símbolo da igualdade, lugar em que cada espectador se torna, por um momento, cidadão: legislador do próprio sentimento, num mundo provisoriamente reconciliado com a natureza.É nesse espaço, carregado de implicações políticas, que se forma e se exerce a crítica de Hazlitt, moldada pelos tempos e ajustada a novas exigências. "Um outsider em relação à boa sociedade de seu tempo", Hazlitt pertence "ao pequeno grupo de artistas, críticos de arte e seus amigos, portanto especialistas, que possuem talento especial para a arte ou a literatura..., que determinam o chamado gosto artístico em voga... e exercem uma influência decisiva no desenvolvimento das artes" 25 . Tendo se separado da pintura, a arte de escrever, por via da crítica, pôde enfim reencontrá-la - nas galerias e exposições públicas.

${ }^{1}$ Este artigo foi redigido no âmbito das atividades ligadas ao programa Capes/Cofecub 754/12 e é baseado no magistral estudo de Francis Haskell, The ephemeral museum. Old master paitings and the rise of the art exhibition, publicado postumamente em 2000 (New Haven:Yale University Press).

${ }^{2}$ William Hazlitt, “On a landscape of Nicolas Poussin”, Table Talk (1821), p. 238. Nova York: Chelsea House, 1983. 
${ }^{3}$ William Hazlitt, "On the pleasure of painting”, Table Talk, p. 17.

${ }^{4}$ Para a transformação do Louvre sob a Revolução, de palácio real a museu público, cf. André Chastel, L'art français. Le temps de l'éloquence, pp. 143 ss. Paris: Flammarion, 2000.

5 “On the pleasure of painting”, Table Talk, pp. 15 - 16.

6 "On the pleasure of painting", Table Talk, p. 16.

7 "On the pleasure of painting", Table Talk, p. 07.

8 "On the pleasure of painting", Table Talk, p. 11;08.

9 "'On the pleasure of painting", Table Talk, p. 12; “On gusto", The round table (1817), vol. II, pp. 20 - 21. Ed. fac-simile de Jonathan Wordsworth. Oxford:Woodstock Books, 1991.

10 "On the pleasure of painting", Table Talk, p. 17.

${ }^{11}$ Cf. Kenneth Clark, The romantic rebellion, cap. 09. Londres: Harper \& Row, 1973.

12 The round table, vol. II, pp. 19 - 20, nota.

${ }^{13}$ Friedrich Schlegel, "Notícia de quadros em Paris”, in: Descriptions de tableuaux, pp. 29 - 30. Tradução de Bénédicte Savoy. Paris: ENSBA, 2001.

${ }^{14}$ Friedrich Schlegel, “Notícia de quadros em Paris”, in: Descriptions de tableuaux, p. 30.

${ }^{15}$ Muito tempo depois, referindo-se a um museu bem diferente, um circunspecto filósofo lamentará “a triste luz do museu do Louvre”. Cf. Merleau-Ponty, A prosa do mundo, p. 100.

16 "On the pleasure of painting", Table talk, pp. $14-15$.

${ }^{17}$ Francis Haskell, The ephemeral museum, p. 55.

18 "On the catalogue raisonné of the British Institution", in: The round table, pp. 215 - 216.

19 “On a landscape of Nicolas Poussin”, in: Table Talk, pp. $232-234$.

20 "William Wordsworth", in: The spirit of the age, p. 149.

21 "On the pleasure of painting", in: Table Talk, p. 14.

22 "Notes of a journey through France and Italy", apud. Tom Paulin, The day-satr of liberty. William Hazlitt's radical style, p. 98. Londres: Faber\&Faber, 1998.

23 “On the Elgin marbles", in: Selected writings, p. 284. Org. Jon Cook. Oxford: University Press, 1991.

24 "Sir Walter Scott", in: The spirit of the age, p. 99. Ed. E. D. Mackerness. 2a ed. Plymouth: Northcote House, 1991. A passagem em questão é uma hábil paráfrase de um conhecido trecho de Shaftesbury, Solilóquio, I, 03.

${ }^{25}$ Nas palavras de Norbert Elias, A peregrinação de Watteau à Ilha do Amor, pp. 36 ss. Rio de Janeiro: Jorge Zahar, 2005. Segundo Elias, se outrora era a "sociedade aristocrática" que arbitrava em questões de gosto, essa função passa a ser exercida pelo crítico profissional, que surge com o advento da sociedade burguesa - no período histórico, acrescentamos, que coincide, em linhas gerais, com o da vida de Hazlitt.

doispontos, Curitiba, São Carlos, vol. 11, n. 1, p.79-89, abril, 2014 


\section{Referências bibliográficas}

CHASTEL, A. 2000. L'art français. Le temps de l'éloquence. Paris:

Flammarion.

CLARL, K.. 1973. The romantic rebellion. Londres: Harper \& Row.

ELIAS, N. 2005. A peregrinação de Watteau à Ilha do Amor. Tradução de Antonio Carlos Santos. Rio de Janeiro: Jorge Zahar.

HASKELL, F. 2000. The ephemeral museum. Old master paitings and the rise of the art exhibition. Ed. Nicholas Penny. New Haven:Yale University Press.

HAZLITT, W. 1983. On a landscape of Nicolas Poussin. Table Talk (1821). Nova York: Chelsea House.

1983. On the pleasure of painting. Table Talk (1821). Nova York:

Chelsea House.

1991. On gusto. The round table (1817). Ed. fac-simile de Jonathan Wordsworth. Oxford:Woodstock Books.

1991. On the catalogue raisonné of the British Institution. The round table (1817), Ed. fac-simile de Jonathan Wordsworth. Oxford: Woodstock Books.

1991. William Wordsworth. The spirit of the age. Ed. E. D.

Mackerness. $2^{\text {a }}$ edição. Plymouth: Northcote House.

1991. On the Elgin marbles. Selected writings. Org. Jon Cook.

Oxford: University Press.

1991. Sir Walter Scott. The spirit of the age. Ed. E. D. Mackerness. $2^{a}$ edição. Plymouth: Northcote House.

PAULIN, T. 1998. The day-star of liberty. William Hazlitt's radical style. Londres: Faber\&Faber.

SCHLEGEL, F. 2001. Notícia de quadros em Paris. In: Descriptions de tableaux. Tradução de Bénédicte Savoy. Paris: ENSBA. 